\title{
SOME AUGMENTED ROW-COLUMN DESIGNS
}

by

W. T. Federer, R. C. Nair and D. Raghavarao

$\mathrm{BU}-519-\mathrm{M}^{3}$

June 1974

\section{ABSTRACT}

A number of specific augmented $n$-row by $n$-column designs for $n=3,4,5,6,7$ for $v$ replicated check varieties and for $v$, unreplicated new varieties, are presented. Most of the designs are constructed such that any unreplicated variety plot is surrounded by two, three, or four replicated variety plots. The designs are compared using the average variance of a difference between unreplicated varieties for specified $v_{1}$ and $n$. Three generalizations of classes of designs are discussed. The specific application discussed pertains to screening new strains in a plant breeding program.

\footnotetext{
*In the Mimeo Series of the Biometrics Unit, Cornell University. Partially supported by a Public Health Research Grant number 5-R01-05900 from the National Institutes of Health.
} 
SOME AUGMENTED ROW-COLUMN DESIGNS

by

W. T. Federer, R. C. Náir and D. Raghavarao

BU-519-M*

June 1974

\section{INTRODUCTION}

Eight sugarcane variety screening trials were designed as plan D-7-4 given below and were installed in Brazil in 1973. Dr. A. J. Mangelsdorf of the Experiment Station of the Hawaiian Sugar Planters' Association, was a consultant on these experiments, and it was he who raised questions about the statistical analysis for such designs. These questions led to a consideration of a group of row-column designs similar to the one he constructed. The purpose of this paper is to present a number of $n$-row by $n$-column designs for $n^{2}$ plots for $n=2,3,4,5,6,7$ which meet the requirement that $n^{2} / 2$ for $n$ even or $\left(n^{2}+1\right) / 2$ for $\mathrm{n}$ odd plots are devoted to replicated check varieties and the remaining $\mathrm{n}^{2} / 2$ for $n$ even or $\left(n^{2}-1\right) / 2$ for $n$ odd plots being devoted to unreplicated trials for testing new strains. The designs also need to meet the requirement that any unreplicated plot is surrounded by three or four check variety plots when $n$ is odd; all unreplicated varieties except two are surrounded by three or four replicated variety plots when $\mathrm{n}$ is even, with the two exceptions being bordered by two replicated variety plots. Some additional row-column designs not meeting the above requirements are included for comparison.

The group of designs considered are presented in section two of the paper. Then, in section three, a randomization procedure is given which retains the

\footnotetext{
*In the Mimeo Series of The Biometrics Unit, Cornell University. Partially supported by a Public Health Research Grant number 5-RO1-05900 from the National Institutes of Health.
} 
requirements of the design. The statistical analysis is presented for each of the designs in the next section. A comparison of the designs with the augmented row-column designs of Federer and Raghavarao [1973] is made for $n=7$ and for the two cases of three and of four check varieties replicated seven times. In the final section some generalizations of specific designs in section two are discussed.

\section{TWO-WAY AUGMENTED ROW-COLUMN DESIGNS FOR $n=3,4,5,6,7$}

In the designs given below let capital letters $A, B, C, \cdots$ represent the $v$ replicated varieties and let the numbers $1,2, \ldots$ represent the $v_{1}$ unreplicated new varieties. Furthermore, let $r_{i}$ denote the number of times the $i^{\text {th }}$ variety is replicated in the $n$-row by $n$-column design; $r_{1}=r_{2}=\ldots=r_{v_{1}}=1$ for each of the unreplicated varieties. Then, the following are some of the available designs with a number of them meeting the requirements stated in the introduction.

For $n=3, v=2$ two possible designs are:

\begin{tabular}{|l|l|l|}
\hline \multicolumn{2}{|c|}{$D-3-1$} \\
\hline$A$ & 1 & $B$ \\
\hline 2 & $A$ & 3 \\
\hline$B$ & 4 & $A$ \\
\hline
\end{tabular}

$$
\begin{aligned}
& v=2 ; r_{A}=3, r_{B}=2 \\
& v_{1}=4 \text { new varieties }
\end{aligned}
$$

\begin{tabular}{|c|c|c|}
\hline \multicolumn{3}{|c|}{$D-3-2$} \\
\hline$A$ & $B$ & $I$ \\
\hline 2 & $A$ & $B$ \\
\hline$B$ & 3 & $A$ \\
\hline
\end{tabular}$$
\mathrm{v}=2 ; r_{\mathrm{A}}=\mathrm{r}_{\mathrm{B}}=3
$$$$
v_{1}=3 \text { new varieties }
$$

For $n=4$ the following designs may be used (new treatments numbered 1 to 8 ): 


\begin{tabular}{|c|c|c|c|}
\hline$A$ & $I$ & $B$ & 2 \\
\hline 3 & $A$ & 4 & $B$ \\
\hline$B$ & 5 & $A$ & 6 \\
\hline 7 & $B$ & 8 & $A$ \\
\hline
\end{tabular}

\begin{tabular}{|c|c|c|c|}
\hline A & D- -2 & $B$ & 2 \\
\hline 3 & $C$ & 4 & $A$ \\
\hline$B$ & 5 & $C$ & 6 \\
\hline 7 & $A$ & 8 & $B$ \\
\hline
\end{tabular}

$$
\begin{aligned}
& v=2 ; r_{A}=4=r_{B} \\
& v_{1}=8 \text { new varieties }
\end{aligned}
$$

$$
\begin{aligned}
& v=3 ; r_{A}=3=r_{B}, r_{C}=2 \\
& v_{1}=8 \text { new varieties }
\end{aligned}
$$

For $n=5$, the following designs may be utilized (new treatments numbered 1 to 12):

\begin{tabular}{|c|c|c|c|c|}
\hline$A$ & 1 & $B$ & 2 & $A$ \\
\hline 3 & $B$ & 4 & $A$ & 5 \\
\hline$B$ & 6 & $A$ & 7 & $B$ \\
\hline 8 & $A$ & 9 & $B$ & 10 \\
\hline$A$ & 11 & $B$ & 12 & $A$ \\
\hline$V=2 ; ~ r_{A}=7, r_{B}=6$ \\
$v_{1}=12$ new varieties
\end{tabular}

\begin{tabular}{|c|c|c|c|c|}
\hline \multicolumn{5}{|c|}{$D-5-3$} \\
\hline A & 1 & $B$ & 2 & $C$ \\
\hline 3 & $D$ & 4 & A & 5 \\
\hline B & 6 & $\mathrm{C}$ & 7 & $D$ \\
\hline 8 & $\mathrm{~A}$ & 9 & B & 10 \\
\hline C & 11 & $D$ & 12 & A \\
\hline
\end{tabular}

\begin{tabular}{|c|c|c|c|c|}
\hline A & 1 & B & 2 & C \\
\hline 3 & A & 4 & B & 5 \\
\hline C & 6 & A & 7 & B \\
\hline 8 & C & 9 & A & 10 \\
\hline B & 11 & C & 12 & A \\
\hline
\end{tabular}

\begin{tabular}{|c|c|c|c|c|}
\hline \multicolumn{5}{|c|}{$D-5-4$} \\
\hline A & 1 & B & 2 & C \\
\hline 3 & $D$ & 4 & $E$ & 5 \\
\hline B & 6 & $C$ & 7 & D \\
\hline 8 & $E$ & 9 & A & 10 \\
\hline C & 11 & $D$ & 12 & $E$ \\
\hline
\end{tabular}

$v=3 ; r_{A}=5, r_{B}=4=r_{C}$

$v_{1}=12$ new varieties 


\begin{tabular}{|c|c|c|c|c|}
\hline A & 1 & C & 2 & D \\
\hline 3 & $D$ & 4 & $B$ & 5 \\
\hline B & 6 & 7 & 8 & A \\
\hline 9 & A & 10 & C & II \\
\hline C & 12 & D & 13 & B \\
\hline
\end{tabular}

(Note that the center plot is surrounded by checks [capital letters] only on the diagonals and not on adjacent sides.)

$\mathrm{v}=4 ; \mathrm{r}_{\mathrm{A}}=\mathrm{r}_{\mathrm{B}}=\mathrm{r}_{\mathrm{C}}=\mathrm{r}_{\mathrm{D}}=3$

$v_{1}=13$ new varieties

For $\mathrm{n}=6$ and $\mathrm{v}_{1}=18$ unreplicated new treatments, the following designs are available:

\begin{tabular}{|c|c|c|c|c|c|}
\hline \multicolumn{6}{|c|}{$D-6-1$} \\
\hline A & 1 & B & 2 & A & 3 \\
\hline 4 & B & 5 & A & 6 & B \\
\hline A & 7 & B & 8 & A & 9 \\
\hline 10 & B & 11 & A & 12 & B \\
\hline B & 13 & A & 14 & B & 15 \\
\hline 16 & A & 17 & B & 18 & A \\
\hline
\end{tabular}

\begin{tabular}{|c|c|c|c|c|c|}
\hline$A$ & 1 & $B$ & 2 & $C$ & 3 \\
\hline 4 & $A$ & 5 & $B$ & 6 & $C$ \\
\hline$B$ & 7 & $C$ & 8 & $A$ & 9 \\
\hline 10 & $C$ & 11 & $A$ & 12 & $B$ \\
\hline$C$ & 13 & $A$ & 14 & $B$ & 15 \\
\hline 16 & $B$ & 17 & $C$ & 18 & $A$ \\
\hline
\end{tabular}

\begin{tabular}{|c|c|c|c|c|c|}
\hline A & 1 & B & 2 & C & 3 \\
\hline 4 & D & 5 & A & 6 & B \\
\hline C & 7 & D & 8 & A & 9 \\
\hline 10 & B & 11 & C & 12 & D \\
\hline B & 13 & C & 14 & D & 15 \\
\hline 16 & A & 17 & B & 18 & C \\
\hline
\end{tabular}

\begin{tabular}{|c|c|c|c|c|c|}
\hline A & 1 & B & 2 & C & 3 \\
\hline 4 & D & 5 & E & 6 & A \\
\hline B & 7 & C & 8 & D & 9 \\
\hline 10 & E & 11 & A & 12 & B \\
\hline C & 13 & D & 14 & E & 15 \\
\hline 16 & A & 17 & B & 18 & C \\
\hline
\end{tabular}

$v=4 ; r_{A}=r_{D}=4, r_{C}=r_{B}=5$

$v=5 ; r_{A}=r_{B}=r_{C}=4, r_{D}=r_{E}=3$ 


C \begin{tabular}{c|c|c|c|c|c|}
\hline$A$ & 1 & $B$ & 2 & $C$ & 3 \\
\hline 4 & $D$ & 5 & $E$ & 6 & $F$ \\
\hline$B$ & 7 & $C$ & 8 & $A$ & 9 \\
\hline 10 & $E$ & 11 & $F$ & 12 & $D$ \\
\hline$C$ & 13 & $A$ & 14 & $B$ & 15 \\
\hline 16 & $F$ & 17 & $D$ & 18 & $E$ \\
\hline $6 ; r_{A}=r_{B}=r_{C}=r_{D}=r_{E}=r_{F}$
\end{tabular}$=3$

For $n=7$, the following designs may be utilized:

\begin{tabular}{|c|c|c|c|c|c|c|}
\hline \multicolumn{7}{|c|}{$D-7-1$} \\
\hline A & 1 & B & 2 & A & 3 & B \\
\hline 4 & A & 5 & B & 6 & A & 7 \\
\hline$B$ & 8 & A & 9 & B & 10 & A \\
\hline 11 & B & 12 & $A$ & 13 & B & 14 \\
\hline A & 15 & B & 26 & A & 17 & B \\
\hline 18 & A & 19 & $B$ & 20 & A & 21 \\
\hline B & 22 & A & 23 & B & 24 & A \\
\hline
\end{tabular}

\begin{tabular}{|c|c|c|c|c|c|c|}
\hline $\mathrm{A}$ & 1 & $\mathrm{~B}$ & 2 & $\mathrm{C}$ & 3 & $\mathrm{~A}$ \\
\hline 4 & $\mathrm{~B}$ & 5 & $\mathrm{C}$ & 6 & $\mathrm{~A}$ & 7 \\
\hline $\mathrm{B}$ & 8 & $\mathrm{C}$ & 9 & $\mathrm{~A}$ & $\mathrm{I}$ & $\mathrm{B}$ \\
\hline $\mathrm{II}$ & $\mathrm{C}$ & 12 & $\mathrm{~A}$ & 13 & $\mathrm{~B}$ & 14 \\
\hline $\mathrm{C}$ & 15 & $\mathrm{~A}$ & 16 & $\mathrm{~B}$ & 17 & $\mathrm{C}$ \\
\hline 18 & $\mathrm{~A}$ & 19 & $\mathrm{~B}$ & 20 & $\mathrm{C}$ & 21 \\
\hline $\mathrm{A}$ & 22 & $\mathrm{~B}$ & 23 & $\mathrm{C}$ & 24 & $\mathrm{~A}$ \\
\hline
\end{tabular}

\begin{tabular}{|c|c|c|c|c|c|c|}
\hline \multicolumn{7}{|c|}{$D-7-3$} \\
\hline A & 1 & B & 2 & $C$ & 3 & $D$ \\
\hline 4 & A & 5 & B & 6 & $\mathrm{C}$ & 7 \\
\hline$D$ & 8 & A & 9 & B & 10 & $C$ \\
\hline 11 & $D$ & 12 & A & 13 & B & 14 \\
\hline C & 15 & D & 16 & A & 117 & $B$ \\
\hline 18 & C & 19 & $D$ & 20 & A & 21 \\
\hline B & 22 & $C$ & 23 & $D$ & 24 & A \\
\hline
\end{tabular}

\begin{tabular}{|r|r|r|r|r|r|c|}
\hline$A$ & $I$ & $B$ & 2 & $C$ & 3 & $D$ \\
\hline 4 & $E$ & 5 & $A$ & 6 & $B$ & 7 \\
\hline$C$ & 8 & $D$ & 9 & $E$ & 10 & $A$ \\
\hline 11 & $B$ & 12 & $C$ & 13 & $D$ & 14 \\
\hline$E$ & 15 & $A$ & 16 & $B$ & 17 & $C$ \\
\hline 18 & $D$ & 19 & $E$ & 20 & $A$ & 21 \\
\hline$B$ & 22 & $C$ & 23 & $D$ & 24 & $E$ \\
\hline
\end{tabular}$=5 ; r_{A}=r_{B}=r_{C}=r_{0}=r_{E}=5$
$v_{1}=24$ new varieties




\begin{tabular}{|c|c|c|c|c|c|c|}
\hline A & 1 & B & 2 & C & 3 & D \\
\hline 4 & E & 5 & F & 6 & A & 7 \\
\hline B & 8 & C & 9 & D & 10 & E \\
\hline II & F & 12 & A & 13 & B & 14 \\
\hline C & 15 & D & 16 & E & 17 & F \\
\hline 18 & A & 19 & B & 20 & C & 21 \\
\hline D & 22 & E & 23 & F & 24 & A \\
\hline
\end{tabular}

D-7-6

\begin{tabular}{|c|c|c|c|c|c|c|}
\hline$A$ & $I$ & $B$ & 2 & $C$ & 3 & $D$ \\
\hline 4 & $E$ & 5 & $F$ & 6 & $G$ & 7 \\
\hline$B$ & 8 & $A$ & 9 & $D$ & 10 & $C$ \\
\hline$I I$ & $F$ & $I 2$ & $G$ & 13 & $E$ & $I 4$ \\
\hline C & 15 & D & I6 & A & I7 & B \\
\hline I8 & G & I9 & E & 20 & F & 21 \\
\hline D & 22 & C & 23 & B & 24 & A \\
\hline
\end{tabular}
$v=6 ; r_{A}=5, r_{B}=r_{C}=r_{D}=r_{E}=r_{F}=4$
$v_{1}=24$ new varieties

\begin{tabular}{|c|c|c|c|c|c|c|}
\hline A & 1 & B & 2 & C & 3 & D \\
\hline D & A & 4 & B & 5 & C & 6 \\
\hline 7 & D & A & 8 & B & 9 & C \\
\hline C & 10 & D & A & 11 & B & 12 \\
\hline I3 & C & 14 & D & A & I5 & B \\
\hline B & 16 & C & I7 & D & A & 18 \\
\hline 19 & B & 20 & C & 21 & D & A \\
\hline
\end{tabular}

\begin{tabular}{|c|c|c|c|c|c|c|}
\hline A & 1 & 2 & B & 3 & C & D \\
\hline D & A & 4 & 5 & B & 6 & C \\
\hline C & D & A & 7 & 8 & B & 9 \\
\hline 10 & C & D & A & 11 & 12 & B \\
\hline B & 13 & C & D & A & 14 & 15 \\
\hline 16 & B & 17 & C & D & A & 18 \\
\hline 19 & 20 & B & 21 & C & D & A \\
\hline
\end{tabular}

$v=4 ; r_{A}=r_{B}=r_{C}=r_{D}=7$

$v=4 ; r_{A}=r_{B}=r_{C}=r_{D}=7$

$v_{I}=21$ new varieties

$v_{1}=21$ new varieties

\begin{tabular}{|r|r|r|r|r|r|r|}
\hline$A$ & $B$ & $I$ & $C$ & 2 & 3 & 4 \\
\hline 5 & A & B & 6 & C & 7 & 8 \\
\hline 9 & 10 & A & B & 11 & C & 12 \\
\hline 13 & 14 & 15 & A & B & 16 & C \\
\hline C & 17 & 18 & 19 & A & B & 20 \\
\hline 21 & C & 22 & 23 & 24 & A & B \\
\hline B & 25 & C & 26 & 27 & 28 & A \\
\hline & $v=3 ; r_{A}=r_{B}=r_{C}=7$ \\
$v_{1}=28$ new varieties
\end{tabular}

\begin{tabular}{|r|r|r|r|r|r|r|}
\hline $\mathrm{A}$ & 1 & $\mathrm{~B}$ & 2 & $\mathrm{C}$ & 3 & 4 \\
\hline 5 & $\mathrm{~A}$ & 6 & $\mathrm{~B}$ & 7 & $\mathrm{C}$ & 8 \\
\hline 9 & 10 & $\mathrm{~A}$ & 11 & $\mathrm{~B}$ & 12 & $\mathrm{C}$ \\
\hline $\mathrm{C}$ & 13 & 14 & $\mathrm{~A}$ & 15 & $\mathrm{~B}$ & 16 \\
\hline 17 & $\mathrm{C}$ & 18 & 19 & $\mathrm{~A}$ & 20 & $\mathrm{~B}$ \\
\hline $\mathrm{B}$ & 21 & $\mathrm{C}$ & 22 & 23 & $\mathrm{~A}$ & 24 \\
\hline 25 & $\mathrm{~B}$ & 26 & $\mathrm{C}$ & 27 & 28 & $\mathrm{~A}$ \\
\hline
\end{tabular}


Designs for other $n, v$, and $v_{I}$ may be constructed following the above procedure. As is indicated in Table 1, the error degrees of freedom for these designs may be quite small or nonexistent. In general, the number of degrees of freedom available for estimating the error mean square is equal to $\left(\sum_{i=1}^{\mathrm{V}} r_{i}=\right.$ number of replicated plots) $-v-2(n-1)$. Only two designs considered, $D-7-7$ and $D-7-8$, have as many as 12 degrees of freedom, but these two designs do not meet the requirement $(i)$ that $n^{2} / 2$ for $n$ even or $\left(n^{2}-1\right) / 2$ for $n$ odd of the plots are devoted to unreplicated plots. All designs meet this requirement except D-3-2, $D-5-5, D-7-7, D-7-8, D-7-9$, and $D-7-10$. In design $D-5-5, v_{1}=\left(n^{2}+1\right) / 2=13$, and this type of design can be constructed easily for any odd $n$ for $(n-1)=v$ check varieties each replicated $(n+1) / 2$ times. For these designs the error degrees of freedom for the exror mean square is equal to $(n-1)(n-6)$. Hence, $n$ should be at least 9 since $n=7$, produces only five degrees of freedom for error.

Designs meeting the requirement that (ii) every new variety be surrounded by three or four check variety plots are $D-3-1, D-3-2, D-5-1, D-5-2, D-5-3, D-5-4$, $D-7-1, D-7-2, D-7-3, D-7-4, D-7-5, D-7-6, D-7-7$, and D-7-8. Designs which meet the requirement that every new variety is surrounded by three or four check variety plots except two which are surrounded by two check variety plots are designs $D-4-1, D-4-2, D-6-1, D-6-2, D-6-3, D-6-4$, and $D-6-5$.

\section{RANDOMIZATION PROCEDURE}

A randomization procedure for the above designs is to proceed as follows:

(i) Randomly allot the even-numbered columns of a plan to the even-numbered columns in the experiment.

(ii) Randomly allot the odd-numbered columns to the odd-numbered columns in the experiment. 
(iii) Randomly allot the even-numbered rows of the plan to the even-numbered rows in the experiment.

(iv) Randomly allot the odd-numbered rows to the odd-numbered rows in the experiment.

(v) Randomly allot the capital letters to the check varieties and then randomly allot the numbers to the new-unreplicated varieties.

This procedure retains the basic arrangement and requirements of the design. Special precaution must be used for designs like $D-5-5$ where the $(n+1) / 2^{\text {th }}$ row and column cannot be allotted to and outside row and column, respectively.

\section{SOLUTIONS FOR PARAMETERS OF DESIGNS AND ANOVA'S}

For the row-column designs considered, suppose that the yield equation is

$$
Y_{h i j}=\mu+\rho_{h}+\gamma_{i}+\tau_{j}+\epsilon_{h i j}
$$

where $\mu$ is a general mean effect, $\rho_{h}$ equals the effect for $h^{\text {th }}$ row, $h=1,2, \cdots, n$, $\gamma_{i}$ equals the effect for $i^{\text {th }}$ column, $i=1,2, \cdots, n, \tau_{j}$ equals the effect of $j^{\text {th }}$ treatment, $j=A, B, \cdots, v, I, 2, \cdots, v_{I}$, the $\epsilon_{h i j}$ equals random error components which are identically and independently distributed with zero mean and variance $\sigma_{\epsilon}^{2}$, and $E\left[Y_{h i j}\right]=\mu+\rho_{h}+\gamma_{i}+\tau$, . The normal equations are obtained by minimizing $\sum_{h=1}^{n} \sum_{i=1}^{n} \sum_{j=1}^{V} n_{h i j} \epsilon_{h i j}^{2}$ where $n_{h i j}$ equals one if $j^{\text {th }}$ check variety is in the $h^{\text {th }}$ row and the $i^{\text {th }}$ column and zero otherwise. As shown by Federer and Raghavarao [1973], the yields for the unreplicated varieties may be ignored in obtaining solutions for the other effects.

A solution for a design $(d)$ is given by $\hat{\tau}^{(d)}=A^{(d)} Q^{(d)}$, where $A^{(d)}$ is a generalized inverse of the matrix: 
and

$$
\begin{aligned}
& D=\operatorname{diag}\left(r_{1}, \ldots, r_{v}\right)-\frac{I}{n} I I^{\prime}-\frac{I}{n} M^{\prime}+\frac{I}{n^{2}}\left[\begin{array}{c}
r_{I} \\
\vdots \\
r_{v^{*}}
\end{array}\right]\left(r_{1} \cdots r_{v^{*}}\right) \\
& Q=B-\frac{1}{n} I R-\frac{I}{n} M C+\frac{I}{n^{2}}\left[\begin{array}{c}
r_{I} \\
\vdots \\
r_{v^{*}}
\end{array}\right] Y \ldots,
\end{aligned}
$$

where

$$
\begin{aligned}
& \mathrm{v}^{*}=v+v_{I}, \\
& B=\text { vector of treatment totals, } \\
& R=a \text { vector of row totals, } \\
& C=\text { a vector of column totals, } \\
& Y . . \text { = a total of all observations, } \\
& r_{j}=\text { number of replicates of } j{ }^{\text {th }} \text { treatment, } \\
& I=\text { row-treatment incidence matrix, and } \\
& M=\text { column-treatment incidence matrix. }
\end{aligned}
$$

The matrix $A^{(d)}$ for each design is given in the appendix for the unreplicated varieties. These were obtained, using the constraint $\sum_{j=I}^{v^{*}} \hat{\tau}_{j}=0$. Variances. of estimable parametric functions may be computed, using this matrix; for example, $V\left(\hat{\tau}_{j}, \hat{\tau}_{j^{\prime}}\right)=\left[A_{j j^{\prime}}+A_{j^{\prime} j^{\prime}}-2 A_{j j^{\prime}}\right]_{\sigma_{\epsilon}^{2}}$ where the element of row $j$ and column $j^{\prime}$ in $A^{(d)}$ is denoted as $A_{j j^{\prime}}$. The procedure is illustrated for design D-3-2, below:

$$
\begin{aligned}
& \text { The yields are: } \\
& \begin{array}{|llll|l} 
& & & \text { Mean } \\
\hline Y_{1 I A} & Y_{12 B} & Y_{131} & \bar{y}_{1 \ldots} \\
Y_{212} & Y_{22 A} & Y_{23 B} & \bar{y}_{2 \ldots} \\
Y_{31 B} & Y_{323} & Y_{33 A} & \bar{y}_{3 \ldots} \\
\hline \bar{y}_{.1 .} & \bar{y}_{.2 .} & \bar{y}_{.3 .} & \bar{y}_{\ldots}
\end{array} \\
& I^{\prime}=\left[\begin{array}{lllll}
1 & 1 & 1 & 0 & 0 \\
1 & 1 & 0 & 1 & 0 \\
1 & 1 & 0 & 0 & 1
\end{array}\right] ; \quad M^{\prime}=\left[\begin{array}{lllll}
1 & 1 & 0 & 1 & 0 \\
1 & 1 & 0 & 0 & 1 \\
1 & 1 & 1 & 0 & 0
\end{array}\right] ; r_{A}=3=r_{B}, \quad r_{1}=r_{2}=r_{3}=1 .
\end{aligned}
$$


Then,

$$
D=\frac{1}{9}\left[\begin{array}{ccccc}
18 & -9 & -3 & -3 & -3 \\
-9 & 18 & -3 & -3 & -3 \\
-3 & -3 & 4 & 1 & 1 \\
-3 & -3 & 1 & 4 & 1 \\
-3 & -3 & 1 & 1 & 4
\end{array}\right]
$$

and

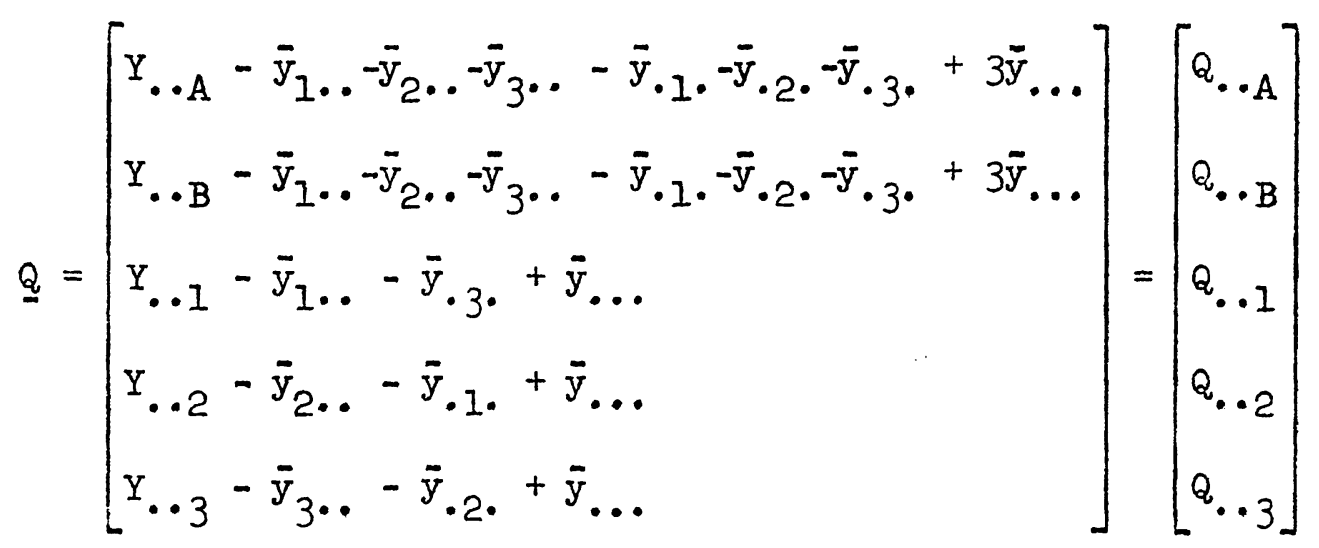

where $Y_{\ldots j}$ is the $j^{\text {th }}$ treatment total. A solution for the variety effects is given by

$$
\hat{\tau}=\left[\begin{array}{c}
\hat{\tau}_{A} \\
\hat{\tau}_{B} \\
\hat{\tau}_{1} \\
\hat{\tau}_{2} \\
\hat{\tau}_{3}
\end{array}\right]=\frac{1}{15}\left[\begin{array}{ccccc}
7 & 2 & 0 & 0 & 0 \\
2 & 7 & 0 & 0 & 0 \\
0 & 0 & 33 & -12 & -12 \\
0 & 0 & -12 & 33 & -12 \\
0 & 0 & -12 & -12 & 33
\end{array}\right]\left[\begin{array}{l}
Q_{. . A} \\
Q_{. B} \\
Q_{\ldots} .1 \\
Q_{\ldots .2} \\
Q_{\ldots 3}
\end{array}\right] .
$$

The various variances of differences between variety effects may be computed from the above matrix as:

$$
\begin{aligned}
& V\left(\hat{\tau}_{\Lambda}-\hat{\tau}_{B}\right)=(7+7-2-2) \sigma^{2} / 15=2 \sigma^{2} / 3 ; \\
& V\left(\hat{\tau}_{A}-\hat{\tau}_{j}\right)=V\left(\hat{\tau}_{B}-\hat{\tau}_{j}\right)=(7+33-0-0) \sigma^{2} / 15=8 \sigma^{2} / 3, j=1,2,3 ; \\
& V\left(\hat{\tau}_{j^{\prime}}-\hat{\tau}_{j^{\prime}}\right)=(33+33-[-12]-[-12]) \sigma^{2} / 15=6 \sigma^{2}, j=1,2,3 .
\end{aligned}
$$


It should be noted that any of the new varieties may be left unharvested and a zero inserted for the yields of those new varieties omitted from the harvest. Since the solution for the row and column effects depends solely upon the replicated check variety yields, the solutions for the differences between check varieties, between check and new varieties retained, and between new varieties retained will not be affected. If zero yields are inserted, formula (4.I) still holds. Likewise, the variance-covariance matrix remains the same, and we can simply drop the rows and columns of the matrix $A^{(d)}$ which pertain to the omitted new varieties; the variances of differences will remain unaffected. For example, suppose that unreplicated varieties $I$ and 2 in design D-3-2 were not harvested. Then, the variance-covariance matrix for the remaining varieties would be:

$$
V\left[\begin{array}{c}
\hat{\tau}_{A} \\
\hat{\tau}_{B} \\
\hat{\tau}_{3}
\end{array}\right]=\left[\begin{array}{lll}
7 & 2 & 0 \\
2 & 7 & 0 \\
0 & 0 & 33
\end{array}\right] \sigma^{2} / 15 \quad \cdot
$$

In variety screening experiments, the dropping of poor performers in an experiment is commonplace. Thus, the fact that the computation of the check variety, the row and the column effects is the same whether or not the unreplicated varieties are included (see Federer and Fighavarao [1973]) is of importance in experiments of this type.

Design $3-1$ is disconnected but is an interesting example for statistical analyses of a disconnected design. The analysis of variance for this design using only the five check variety yields is: 
D.F. Sum of Squares

$\begin{array}{lll}\begin{array}{l}\text { Correction for mean (ignoring } \\ \text { all else) }\end{array} & \text { I } & {\left[Y_{11 A}+Y_{13 B}+Y_{22 A}+Y_{31 B}+Y_{33 A}=Y_{1 .}\right]^{2} / 5} \\ \begin{array}{l}\text { Rows (ignoring varieties and } \\ \text { coivinis) }\end{array} & 2 \frac{\left(Y_{11 A}+Y_{13 B}\right)^{2}}{2}+\frac{Y_{22 A}^{2}}{1}+\frac{\left(Y_{3 i B}+Y_{33 A}\right)^{2}}{2}-Y^{2} \\ \begin{array}{l}\text { Colimns (eliminating rows and } \\ \text { mean) = columns I versus 3 }\end{array} & 1 & {\left[Y_{11 A}+Y_{31 B}-Y_{13 B}-Y_{33 A}\right]^{2} / 4} \\ \begin{array}{l}\text { Variety A versus B (eliminating } \\ \text { all other effects) }\end{array} & 1 & {\left[Y_{11 A}+Y_{33 A}-Y_{31 B}-Y_{13 B}\right]^{2} / 4}\end{array}$

In terms of orthogonal contrasts, the above may be written as:

\begin{tabular}{l|ccccc|}
\multicolumn{1}{c|}{ Contrast } & $Y_{11 \mathrm{~A}}$ & $Y_{13 \mathrm{~B}}$ & $Y_{22 \mathrm{~A}}$ & $Y_{31 \mathrm{~B}}$ & $Y_{33 \mathrm{~A}}$ \\
\hline Correction for mean & + & + & + & + & + \\
Row 1 versus row 3 & + & + & 0 & - & - \\
Rows 1 + 3 versus row 2 & + & + & -4 & + & + \\
Column I versus column 3 & + & - & 0 & + & - \\
Variety A versus variety B & + & - & 0 & - & + \\
\hline
\end{tabular}

It should be noted that designs $D-3-1, D-4-2, D-6-5$, and D-7-6 are not overall connected. The generalized inverse was obtained with the particular computer program used. The computer output gives the rank of the input matrix, or equivalently, the number of estimable contrasts but not the estimable contrasts themselves. For each of the designs, the generalized inverse part of the matrix for the new treatments is given in the appendix. Because of the symmetry of the matrices, only the top (or bottom) part of the matrix above (or below) the diagonal elements is given. Thus, it was possible to put two matrices on each page. The average variance of a difference between two unreplicated varieties may be computed as:

$2\left\{\left(v_{I}-I\right)\right.$ (sum of diagonal elements) - sum of off-diagonal elements\}/ $v_{I}\left(v_{I}-1\right)$. 


\section{COMPARISON OF DESIGNS FOR SPECIFIED $n$}

As stated by Federer and Raghavarao [1973] there are four ways in which these designs may be compared; that is, through

(i) A comparison of variances of estimable contrasts of replicated or check varieties.

(ii) A comparison of variances of estimable contrasts among the unreplicated or new varieties.

(iii) A comparison of variances of estimable contrasts of check varieties versus new varieties.

(iv) A comparison of variances of estimable contrasts among all varieties.

These authors chose (ii) in describing a class of optimal row-column designs. In screening experiments one might wish to use (iii) in comparing new varieties with check varieties. However, here we shall use (ii) even though one may use any of the four comparisons.

The average variance of a difference between estimated new variety effects was computed using formula (4.2) for each of the designs. The results are presented in Table 1 where each design, its type if balanced or orthogonal, values for $v_{I}$, values for degrees of freedom for estimating the error variance and replication numbers for the various check varieties are also given.

In studying the results of Table 1 , one should note that if there were no row and column effects and if a completely randomized design had been used the variance of a difference between two new variety effects would be $2 \sigma^{2}$. For the designs discussed herein, only one, D-7-8, has an average variance as small as $3.200^{2}$ with the next best one being $D-7-10$ where the average variance is $3 \cdot 590^{2}$. As $n$ increases and for designs of type $\mathrm{X}: 00$ or $\mathrm{T}: 00$, the average error variance 
Table 1. Average coefficient of the variance of a difference between two new varieties

\begin{tabular}{|c|c|c|c|c|c|}
\hline Type & Design & $\begin{array}{l}\text { No. of new } \\
\text { varieties }\end{array}$ & $\begin{array}{l}\text { Degrees } \\
\text { of } \\
\text { freedom }\end{array}$ & $\begin{array}{c}\text { (Average } \\
\text { variance)/的 }\end{array}$ & Replication numbers \\
\hline$x: 00$ & $\begin{array}{l}D-4-1 \\
D-4-2 \\
D-5-1 \\
D-5-2 \\
D-5-3 \\
D-5-4 \\
D-5-5\end{array}$ & $\begin{array}{r}8 \\
8 \\
12 \\
12 \\
12 \\
12 \\
13\end{array}$ & $\begin{array}{r}0 \\
-1 \\
3 \\
2 \\
1 \\
0 \\
0\end{array}$ & $\begin{array}{l}4.57 \\
4.27 \\
4.06 \\
4.44 \\
5.15 \\
7.57 \\
5.35\end{array}$ & $\begin{array}{l}r_{A}=r_{B}=4 \\
r_{A}=r_{B}=3, r_{C}=2 \\
r_{A}=7, r_{B}=6 \\
r_{A}=5, r_{B}=r_{C}=4 \\
r_{A}=4, r_{B}=r_{C}=r_{D}=3 \\
r_{A}=r_{B}=2, r_{C}=r_{D}=r_{E}=3 \\
r_{A}=r_{B}=r_{C}=r_{D}=3\end{array}$ \\
\hline$X: T T$ & $D-6-1$ & 18 & 6 & $4 \cdot 34$ & $r_{A}=r_{B}=9$ \\
\hline$X: 00$ & $\begin{array}{l}D-6-2 \\
D-6-3 \\
D-6-4 \\
D-6-5\end{array}$ & $\begin{array}{l}18 \\
18 \\
18 \\
18\end{array}$ & $\begin{array}{l}5 \\
4 \\
3 \\
4 *\end{array}$ & $\begin{array}{l}4.00 \\
4.21 \\
5.16 \\
4.24\end{array}$ & $\begin{array}{l}r_{A}=r_{B}=r_{C}=6 \\
r_{A}=r_{B}=4, r_{C}=r_{D}=5 \\
r_{A}=r_{B}=r_{C}=4, r_{D}=r_{E}=3 \\
r_{A}=r_{B}=r_{C}=r_{D}=r_{E}=r_{F}=3\end{array}$ \\
\hline $\mathrm{X}: \mathrm{TT}$ & $\begin{array}{l}D-7-1 \\
D-7-2 \\
D-7-3 \\
D-7-4 \\
D-7-5 \\
D-7-6\end{array}$ & $\begin{array}{l}24 \\
24 \\
24 \\
24 \\
24 \\
24\end{array}$ & $\begin{array}{r}11 \\
10 \\
9 \\
8 \\
7 \\
8 * *\end{array}$ & $\begin{array}{l}3.81 \\
3.83 \\
3.86 \\
4.07 \\
4.61 \\
4.01\end{array}$ & $\begin{array}{l}r_{A}=13, r_{B}=12 \\
r_{A}=9, r_{B}=r_{C}=8 \\
r_{A}=7, r_{B}=r_{C}=r_{D}=6 \\
r_{A}=r_{B}=r_{C}=r_{D}=r_{E}=5 \\
r_{A}=5, r_{B}=r_{C}=r_{P}=r_{E}=r_{F}=4 \\
r_{A}=r_{B}=r_{C}=r_{D}=4, r_{E}=r_{F}=r_{G}=3\end{array}$ \\
\hline$X: 00$ & $D-7-7$ & 21 & 12 & $3 \cdot 63$ & $r_{A}=r_{B}=r_{C}=r_{D}=7$ \\
\hline $\mathrm{T}: 00$ & $D-7-8$ & 21 & 12 & $3 \cdot 20$ & $r_{A}=r_{B}=r_{C}=r_{D}=7$ \\
\hline $\mathrm{T}: 00$ & $D-7-9$ & 28 & 6 & $3 \cdot 78$ & $r_{A}=r_{B}=r_{C}=7$ \\
\hline$x: 00$ & $D-7-10$ & 28 & 6 & $3 \cdot 59$ & $r_{A}=r_{B}=r_{C}=7$ \\
\hline
\end{tabular}

* O denotes orthogonality, $T$ denotes balance, and $X$ denotes unknown balance where the relationships are in the order rows-columns-varieties.

One check variety, one row, and one column contrast are completely confounded with each other. 
approaches $2 \sigma^{2}$. Also, one should note the relatively small number of degrees of freedom available for error for $n=7$. Only four designs, $D-7-1, D-7-2$, $D-7-7$, and $D-7-8$, have ten or more degrees of freedom available for error. This may not be serious, if there are several sets of experiments and the errors for the experiments can be pooled. Designs with $n=8$ and 9 should have sufficient degrees of freedom for error estimation.

A rather surprising result from the examples is that the average variance of a difference for design $D-7-10$ is smaller than design $D-7-9$, whereas it is smaller for $D-7-8$ as compared to $D-7-7$. One would expect that if the rovs and columns were in a balanced arrangement with each other that the average variance would be smaller. However, this is not the case and it would appear that the average variance also depends upon how many unreplicated plots are surrounded by replicated ones. Thus, the optimal row-column designs of Federer and Raghavarao [1973] are variance optimal for estimating row and column effects but are not variance optimal for estimating the average variance between new treatments. The Mangelsdorf criterion of surrounding unreplicated plots with replicated plots appears to have variance-optimality properties. However, note that the average variance of a difference within rows and within columns is smaller for $D-7-8$ and $D-7-9$ than for $D-7-7$ and $D-7-10$, respectively.

For constant $v_{1}$ and $n$, several comparisons are possible from Table 1 . For example, for $v_{1}=18$ and $n=6, D-6-2$ has the smallest average error variance, has next to the largest error degrees of freedom, and is equi-replicated for three check varieties. For $v_{1}=24, D-7-1$ has the smallest average error, has the largest number of error degrees of freedom, and has the fewest check varieties. In general, as $v$ tends to increase so does the average error, but there are exceptions caused by orthogonality and perhaps other items. D-5-4 has the highest average variance, 7.57 , owing to the nonorthogonality of the check varieties with rows and columns and to the small replication number of the check varieties. 


\section{SOME POSS IBLE GENERALIZATIONS}

It should be noted that analyses for specific designs are given in this paper. There are, however, some general classes of augmented row-column designs that could be considered. Three such classes are described below. The straightforward analyses and solutions are not given herein. If a need arises, they can quickly and easily be obtained.

For the first class of augmented row-column designs, consider the following: for $n$ even, $v=n / 2$ checks with $r=n$ replicates, and for $v_{1}=n^{2} / 2$ new treatments, it would be possible to obtain an analysis for any $n$ given that the $v=n / 2$ checks were designed in an $\mathrm{n} / 2 \times \mathrm{n} / 2$ latin square in the odd rows and odd columns and in an $\mathrm{n} / 2 \times \mathrm{n} / 2$ latin square in the even rows and even columns. Designs $D-4-I$ and $D-6-2$ are members of this class of designs.

For the second class of augmented row-column designs, we consider the following: for $n$ even, $v=n, r=n / 2$, and for $v_{1}=n^{2} / 2$ new varieties it would be possible to construct a row-column design for which the treatments formed a groupdivisible design with rows and a group-divisible design with columns. An example follows:

\begin{tabular}{|c|c|c|c|}
\hline$A$ & $I$ & $B$ & 2 \\
\hline 3 & C & 4 & D \\
\hline C & 5 & A & 6 \\
\hline 7 & D & 8 & B \\
\hline
\end{tabular}

This design is not connected; therefore $n$ must be greater than four.

A third class of augmented row-column designs could be obtained for the following situation: for $n$ odd, $v=n=2$ check varieties with $r=(v+5) / 2=v-k$ replicates on $v-k$ of the entries and with $r=(v+5) / 2-1$ replicates on the remaining $k$ 
checks for $k=(v-5) / 2=(n-7) / 2$, and with $v_{1}=\left(n^{2}-1\right) / 2$ new varieties. Designs $D-5-2$ and $D-7-4$ are of this type (the Mangelsdorf type). The $n-2$ check varieties enter cyclically in the $n \times n$ square. For $n=5$ it should be noted that $k$ is a negative one. This means that one check variety is replicated five times and two varieties are replicated four times each. The above formula then holds for odd $n \geq 7$.

Still other classes of augmented row-column designs could be constructed. For example, instead of squares rectangular designs could be used. If rows 5 and 6 are deleted from D-6-2, then a 4 -row by 6 -column design is formed such that instead of latin squares in odd rows and columns and in the even rows and columns, a Youden design is formed. These problems are left as future research topics.

\section{REFTPENCE}

Federer, W.T. and D. Raghavarao [1973]. On augmented designs. N:xmber BU-480 M in tre Mineo Series of the Biometrics Unit, Cornell University (to appear in Biometrics). 


$$
\text { D-4-1 }
$$

Average variation of a treatment difference $=4.5714$

\begin{tabular}{|rrrrrrrr|}
\hline 2875 & 875 & -875 & -375 & 1375 & 375 & -875 & -375 \\
& 1875 & -375 & 125 & 375 & 375 & -375 & 125 \\
1889 & & 2875 & 875 & -875 & -375 & 1375 & 375 \\
1111 & 1889 & & 1875 & -375 & 125 & 375 & 375 \\
-333 & 1333 & 5000 & & 2875 & 875 & -875 & -375 \\
-111 & 1111 & 2667 & 1889 & & 1875 & -375 & 125 \\
1111 & -111 & -1667 & -889 & 889 & & 2875 & 875 \\
333 & 667 & 000 & 333 & 667 & 1000 & & 1875 \\
-111 & 2111 & 5667 & 2889 & -1889 & -333 & 7889 & \\
111 & 1889 & 3333 & 2111 & -1111 & -667 & 5111 & 3889 \\
\hline
\end{tabular}

Average variation of a treatment difference $=4.274$

$$
\text { D-4-2 }
$$

Not all functions are estimable 
D-5-1

Average variation of a treatment difference $=4.06484$

\begin{tabular}{rrrrrrrrrrrrr|}
\hline 2773 & 773 & -690 & -787 & -360 & 13467 & 347 & -690 & -787 & -360 & 1440 & 440 \\
& 1773 & -190 & -287 & 140 & 347 & 347 & -190 & -287 & 140 & 440 & 440 \\
2593 & & 2507 & 1113 & 840 & -303 & -253 & 1007 & 613 & 340 & -693 & -193 \\
593 & 1759 & & 2427 & 780 & -807 & -307 & 613 & 927 & 280 & -787 & -287 \\
-778 & 056 & 3167 & & 1840 & -420 & 080 & 340 & 280 & 340 & -360 & 140 \\
-778 & 056 & 1833 & 3167 & & 2627 & 627 & -753 & -807 & -420 & 1347 & 347 \\
-444 & 389 & 1500 & 1500 & 2500 & & 1627 & -253 & -307 & 080 & 347 & 347 \\
1259 & 259 & -778 & -778 & -444 & 2593 & & 2507 & 1113 & 840 & -693 & -193 \\
259 & 426 & 056 & 056 & 389 & 593 & 1759 & & 1147 & 780 & -787 & -287 \\
-778 & -111 & 1333 & 1000 & 667 & -778 & -111 & 2667 & & 1840 & -360 & 140 \\
-778 & -111 & 1000 & 1333 & 667 & -778 & -111 & 1333 & 2667 & & 2773 & 773 \\
-444 & 222 & 667 & 667 & 667 & -444 & 222 & 1000 & 1000 & 2000 & & 1773 \\
1259 & 259 & -778 & -778 & -444 & 1259 & 259 & -778 & -778 & -444 & 2593 & \\
259 & 426 & 056 & 056 & 389 & 259 & 426 & -111 & -111 & 222 & 593 & 1759 \\
\hline
\end{tabular}

Average variation of a treatment difference $=4.44466$

$D-5-2$ 


\section{$\underline{D-5-3}$}

Average variation of a treatment difference $=5.14990$

\begin{tabular}{|rrrrrrrrrrrrr|}
\hline 2775 & 775 & -686 & -784 & -353 & 1343 & 343 & -686 & -784 & -353 & 1441 & 441 \\
& 2150 & 439 & 216 & 522 & 218 & 593 & 814 & 591 & 897 & 191 & 566 \\
3513 & & 3591 & 1961 & 1507 & -983 & 142 & 2716 & 2086 & 1632 & -1103 & 022 \\
753 & 2313 & & 3098 & 1294 & -980 & 020 & 1961 & 2098 & 1294 & -1118 & -118 \\
-1113 & 847 & 4713 & & 2257 & -556 & 309 & 1382 & 1169 & 1132 & -603 & 272 \\
-607 & 473 & 2407 & 3353 & & 2679 & 554 & -1108 & -1105 & -691 & 1427 & 302 \\
-400 & 400 & 1400 & 1200 & 2000 & & 1804 & 392 & 270 & 559 & 177 & 427 \\
2687 & 047 & -2087 & -993 & -600 & 5113 & & 5215 & 3461 & 2882 & -1353 & 147 \\
927 & 607 & -127 & 087 & 200 & 1473 & 2153 & & 4473 & 2544 & -1368 & 007 \\
-1873 & 1407 & 4673 & 2487 & 1200 & -3727 & -447 & 8953 & & 3382 & -853 & 397 \\
-1367 & 1033 & 3367 & 2433 & 1000 & -2633 & -233 & 5767 & 5833 & & 2941 & 691 \\
-1160 & 960 & 2360 & 1280 & 800 & -2240 & -120 & 4480 & 3400 & 3920 & & 1816 \\
2560 & -360 & -2760 & -1480 & -800 & 3840 & 920 & -4680 & -3400 & -2720 & 5520 & \\
800 & 200 & -800 & -400 & 000 & 1200 & 600 & -1400 & -1000 & -600 & 1600 & 2000 \\
\hline
\end{tabular}

Average variation of a treatment difference $=7.57164$

$$
\underline{D-5-4}
$$


$\underline{D-5-5}$

Average variation of a treatment difference $=5.35192$

\begin{tabular}{|c|c|c|c|c|c|c|c|c|c|c|c|c|c|c|c|c|c|}
\hline 3275 & 775 & -1275 & -1450 & -875 & 1850 & -225 & 350 & -975 & -1150 & -575 & 1675 & 175 & & & & & \\
\hline & 1875 & 025 & -250 & 225 & 450 & 075 & 550 & 325 & 050 & 525 & 375 & 475 & & & & & \\
\hline 2392 & & 3675 & 2050 & 1675 & -1050 & 625 & 250 & 2375 & 1750 & 1375 & -1075 & 225 & & & & & \\
\hline 1132 & 2569 & & 3500 & 1450 & -1100 & 1150 & 100 & 1650 & 2100 & 1050 & -1250 & -060 & & & & & \\
\hline 725 & 798 & 1726 & & 2475 & -650 & 425 & 450 & 1175 & 950 & 975 & -675 & 425 & & & & & \\
\hline-618 & -596 & -285 & 2236 & & 3500 & 650 & 1100 & -850 & -900 & -450 & 1650 & 250 & & & & & \\
\hline-691 & -701 & -356 & 882 & 2226 & & 2675 & 950 & 925 & 1450 & 725 & -225 & 075 & & & & & \\
\hline-285 & -264 & 049 & 569 & 549 & 1569 & & 2300 & 450 & 300 & 650 & 350 & 550 & & & & & \\
\hline 1059 & 799 & 392 & -618 & -691 & -285 & 2392 & & 4675 & 2950 & 2475 & -975 & 325 & & & & & \\
\hline 799 & 1236 & 465 & -597 & -701 & -264 & 1132 & 2569 & & 4300 & 2150 & -1150 & 050 & & & & & \\
\hline 392 & 465 & 392 & -284 & -358 & 049 & 726 & 799 & 1726 & & 3075 & -575 & 525 & & & & & \\
\hline-618 & -597 & -285 & 903 & 549 & 236 & -618 & -597 & -285 & 2236 & & 2875 & 575 & & & & & \\
\hline-691 & -701 & -358 & 549 & 882 & 215 & -691 & -701 & -358 & 882 & 22266 & & 1875 & & & & & \\
\hline-285 & -264 & 049 & 236 & 215 & 236 & -285 & -264 & 049 & 569 & 549 & 1569 & & & & & & \\
\hline 986 & 694 & 319 & -639 & -681 & -306 & 986 & 694 & 319 & -639 & -681 & -306 & 2278 & & & & & \\
\hline 726 & 1132 & 392 & -618 & -691 & -285 & 726 & 1132 & 392 & -618 & -691 & -285 & 986 & 2392 & & & & \\
\hline 319 & 361 & 319 & -306 & -347 & 028 & 319 & 361 & 319 & -306 & -347 & 028 & 611 & 653 & 1611 & & & \\
\hline-545 & -493 & -212 & 924 & 538 & 257 & -545 & -493 & -212 & 924 & 538 & 257 & -597 & -545 & -264 & 2309 & & \\
\hline-618 & -597 & -285 & 569 & 882 & 236 & -618 & -597 & -285 & 569 & 882 & 236 & -639 & -618 & -306 & 361 & 2236 & \\
\hline-212 & -160 & 122 & 257 & 205 & 257 & -212 & -160 & 122 & 257 & 205 & 257 & -264 & -212 & 069 & 642 & 590 & 1642 \\
\hline
\end{tabular}

Average variation of a treatment difference $=4.34056$

D-6-1 
$\underline{D-6-2}$

Average variation of a treatment difference $=4.0000$

\begin{tabular}{|rrrrrrrrrrrrrrrrrrr|}
\hline 2333 & 1000 & 667 & -556 & -556 & -222 & 1000 & 667 & 333 & -556 & -556 & -222 & 1000 & 667 & 333 & -556 & -556 & -222 \\
& 2333 & 667 & -556 & -556 & -222 & 667 & 1000 & 333 & -556 & -556 & -222 & 667 & 1000 & 333 & -556 & -556 & -222 \\
2749 & & 1667 & -222 & -222 & 111 & 333 & 333 & 333 & -222 & -222 & 111 & 333 & 333 & 333 & -222 & -222 & 111 \\
1525 & 3033 & & 2333 & 1000 & 667 & -556 & -556 & -222 & 1000 & 667 & 333 & -556 & -556 & -222 & 1000 & 667 & 333 \\
983 & 1117 & 1950 & & 2333 & 667 & -556 & -556 & -222 & 667 & 1000 & 333 & -556 & -556 & -222 & 667 & 1000 & 333 \\
-323 & -208 & 000 & 2615 & & 1667 & -222 & -222 & 111 & 333 & 333 & 333 & -222 & -222 & 111 & 333 & 333 & 333 \\
-531 & -458 & -167 & 1156 & 2448 & & 2333 & 1000 & 667 & -556 & -556 & -222 & 1000 & 667 & 333 & -556 & -556 & -222 \\
-108 & -033 & 217 & 792 & 708 & 1700 & & 2333 & 667 & -556 & -556 & -222 & 667 & 1000 & 333 & -556 & -556 & -222 \\
1296 & 1033 & 533 & -479 & -646 & -200 & 2575 & & 1667 & -222 & -222 & 111 & 333 & 333 & 333 & -222 & -222 & 111 \\
1073 & 1542 & 667 & -365 & -573 & -125 & 1312 & 2781 & & 2333 & 1000 & 667 & -556 & -556 & -222 & 1000 & 667 & 333 \\
531 & 625 & 500 & -156 & -281 & 125 & 812 & 906 & 1781 & & 2333 & 667 & -556 & -556 & -222 & 667 & 1000 & 333 \\
-421 & -283 & -033 & 1271 & 854 & 450 & -575 & -438 & -188 & 2658 & & 1667 & -222 & -222 & 111 & 333 & 333 & 333 \\
-629 & -533 & -200 & 812 & 1146 & 367 & -742 & -646 & -312 & 1242 & 2575 & & 2333 & 1000 & 667 & -556 & -556 & -222 \\
-206 & -108 & 183 & 448 & 406 & 358 & -296 & -198 & 094 & 838 & 796 & 1748 & & 2333 & 667 & -556 & -556 & -222 \\
1206 & 942 & 483 & -448 & -573 & -192 & 1129 & 865 & 406 & -504 & -629 & -248 & 2415 & & 1667 & -222 & -222 & 111 \\
983 & 1450 & 617 & -333 & -500 & -117 & 867 & 1333 & 500 & -367 & -533 & -150 & 1150 & 2617 & & 2333 & 1000 & 667 \\
442 & 533 & 450 & -125 & -208 & 133 & 367 & 458 & 375 & -117 & -200 & 142 & 692 & 783 & 1700 & & 2333 & 667 \\
-213 & -033 & 133 & 1396 & 896 & 533 & -408 & -229 & -062 & 1408 & 908 & 546 & -379 & -200 & -033 & 2908 & & 1667 \\
-421 & -283 & -033 & 938 & 1188 & 450 & -575 & -438 & -188 & 992 & 1242 & 504 & -504 & -367 & -117 & 1408 & 2658 & \\
002 & 142 & 350 & 573 & 448 & 442 & -129 & 010 & 219 & 588 & 463 & 456 & 456 & 017 & 225 & 1046 & 921 & 1915 \\
\hline
\end{tabular}

Average variation of a treatment difference $=4.20568$

$\underline{D-6-3}$ 


\section{D-6-4}

Average variation of a treatment difference $=5.15588$

\begin{tabular}{|rrrrrrrrrrrrrrrrrrr|}
\hline 2407 & 980 & 703 & -507 & -450 & -143 & 1130 & 703 & 427 & -600 & -543 & -237 & 1103 & 677 & 400 & -543 & -487 & -180 \\
& 2377 & 823 & -180 & -233 & -037 & 593 & 990 & 437 & -117 & -170 & 027 & 457 & 853 & 300 & -003 & -057 & 140 \\
2444 & & 2068 & 547 & 458 & 545 & 282 & 402 & 647 & 667 & 578 & 665 & 035 & 155 & 400 & 912 & 823 & 910 \\
1111 & 2444 & & 3907 & 2300 & 1493 & -780 & -453 & 273 & 2900 & 2293 & 1487 & -1253 & -927 & -200 & 3293 & 2687 & 1880 \\
778 & 778 & 1778 & & 3492 & 1408 & -592 & -375 & 312 & 2183 & 2375 & 1292 & -1008 & -792 & -100 & 2542 & 2733 & 1650 \\
-667 & -667 & -333 & 2444 & & 2248 & -228 & -122 & 460 & 1267 & 1182 & 922 & -488 & -382 & 200 & 1515 & 1430 & 1170 \\
-667 & -667 & -333 & 1111 & 2444 & & 2652 & 1115 & 803 & -983 & -795 & -432 & 1348 & 812 & 500 & -962 & -773 & -410 \\
-333 & -333 & 0000 & 778 & 778 & 1778 & & 2402 & 813 & -500 & -422 & -168 & 702 & 988 & 400 & -422 & -343 & -090 \\
1111 & 778 & 444 & -667 & -667 & -333 & 2444 & & 2023 & 283 & 327 & 470 & 280 & 290 & 500 & 493 & 537 & 680 \\
778 & 1111 & 444 & -667 & -667 & -333 & 1111 & 2444 & & 4717 & 3000 & 2083 & -1567 & -1083 & -300 & 3833 & 3117 & 1970 \\
444 & 444 & 444 & -333 & -333 & 0000 & 778 & 778 & 1778 & & 4082 & 1888 & -1322 & -948 & -200 & 3082 & 3163 & 2200 \\
-667 & -667 & -333 & 1111 & 778 & 444 & -667 & -667 & -333 & 2444 & & 2518 & -802 & -538 & 100 & 2055 & 1860 & 1490 \\
-667 & -667 & -333 & 778 & 1111 & 444 & -667 & -667 & -333 & 1111 & 2444 & & 2868 & 1222 & 800 & -1655 & -1410 & -890 \\
-333 & -333 & 0000 & 444 & 444 & 444 & -333 & -333 & 0000 & 778 & 778 & 1778 & & 2398 & 700 & -1115 & -980 & -570 \\
1111 & 778 & 444 & -667 & -667 & -333 & 1111 & 778 & 444 & -667 & -667 & -333 & 2444 & & 1800 & -200 & -100 & 200 \\
778 & 1111 & 444 & -667 & -667 & -333 & 778 & 1111 & 444 & -667 & -667 & -333 & 1111 & 2444 & & 5748 & 3997 & 2970 \\
444 & 444 & 444 & -333 & -333 & 0000 & 444 & 444 & 444 & -333 & -333 & 0000 & 778 & 778 & 1778 & & 5043 & 2740 \\
-667 & -667 & -333 & 1111 & 778 & 444 & -667 & -667 & -333 & 1111 & 778 & 444 & -667 & -667 & -333 & 2444 & & 3260 \\
-667 & -667 & -333 & 778 & 1111 & 444 & -667 & -667 & -333 & 778 & 1111 & 444 & -667 & -667 & -333 & 1111 & 2444 & \\
-333 & -333 & 0000 & 444 & 444 & 444 & -333 & -333 & 0000 & 444 & 444 & 444 & -333 & -333 & 0000 & 778 & 778 & 1778 \\
\hline
\end{tabular}

Average variation of a treatment difference $=4.23498$

D-6-5 
D-7-7 Average variation of a treatment difference $=3.63290$

\begin{tabular}{|c|c|c|c|c|c|c|c|c|c|c|c|c|c|c|c|c|c|c|c|c|}
\hline \multirow[t]{2}{*}{$174 a$} & 478 & 48 & 62 & 039 & 03 & 03 & 129 & 099 & 448 & 63 & 098 & 039 & -051 & 062 & 78 & 214 & 129 & -062 & -074 & -0 \\
\hline & 1754 & 478 & -074 & -074 & -039 & 099 & 478 & 202 & 099 & -039 & -005 & -005 & -03 & 098 & 202 & 478 & 098 & -039 & -074 & 071. \\
\hline 1774 & & 1742 & -051 & -074 & -062 & 129 & 214 & 478 & 062 & -051 & -039 & 098 & 062 & 448 & 99 & 29 & .003 & $-\infty 03$ & -039 & -062 \\
\hline 429 & 1714 & & 1742 & 478 & 448 & -003 & -062 & קנב & 3 & $1<>$ & 098 & 098 & 448 & 062 & -039 & $-\infty 1$ & 062 & 129 & 478 & $c 1-$ \\
\hline 429 & 429 & 1714 & & 1754 & 478 & -039 & -074 & -074 & 098 & 478 & 202 & -005 & 098 & 039 & -005 & .039 & 098 & 098 & 202 & 478 \\
\hline 071 & 429 & 071 & 1714 & & 1742 & -062 & 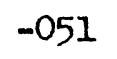 & -074 & 29 & 2 & 478 & 039 & $\alpha$ & 5 & 0 & a & +48 & 3 & 09 & 129 \\
\hline 000 & o71 & 000 & 429 & 1714 & & 1742 & 448 & & -062 & -051 & -074 & 478 & 129 & 214 & 039 & $\infty 62$ & 051 & 448 & 098 & 062 \\
\hline 000 & 071 & $\infty$ & 429 & 429 & 1714 & & 1742 & 478 & -003 & 06 & -039 & 099 & $-\infty$ & 129 & 098 & 1.1. 8 & 062 & 962 & .039 & -051 \\
\hline 000 & $\infty 00$ & 071 & OT1 & 429 & 071 & 1714 & & 4 & -039 & -074 & -074 & 202 & 098 & 478 & -005 & 098 & .039 & 098 & -005 & -039 \\
\hline 071 & 071 & 429 & 000 & 071 & $\infty 00$ & 429 & 1714 & & 1742 & 448 & 478 & -074 & -062 & .051 & 478 & 129 & 214 & -051 & -039 & 062 \\
\hline 000 & 000 & 071 & $\infty 00$ & 071 & $\infty 00$ & 429 & 429 & 1714 & & 1742 & 478 & -039 & .003 & -062 & 098 & .003 & 129 & 062 & 098 & .48 \\
\hline 000 & $\infty 00$ & 71 & 000 & 000 & 071 & $\infty$ & 071 & 000 & 1714 & & 1754 & -074 & -039 & -074 & 202 & 098 & 478 & -039 & .005 & 098 \\
\hline 071 & 11 & $+<>$ & 000 & $\infty 00$ & 071 & 071 & 429 & 11 & 429 & 171 & & 1754 & $\operatorname{lin} 2$ & 478 & -074 & 9 & -074 & 17 & $c^{2}$ & 30 \\
\hline 000 & 000 & 071 & 071 & OT1 & 429 & 000 & 071 & 000 & 000 & 429 & 1714 & & 1742 & 448 & -074 & -062 & -051 & 214 & 478 & 129 \\
\hline 429 & 071 & 011 & 000 & 0 & 071 & 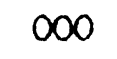 & $\infty 00$ & 071 & 071 & $\infty 00$ & 0 & 1 & & 1742 & קנכ & -003 & 2 & $1<9$ & 8 & -003 \\
\hline 071 & 000 & $\infty 00$ & 071 & 071 & 429 & $\infty 00$ & $\infty$ & 071 & $\infty$ & 071 & 429 & 429 & 1714 & & 1754 & 478 & 478 & -074 & .074 & -039 \\
\hline 071 & 000 & On & $m$ & 000 & 071 & 071 & 071 & 429 & 000 & $\alpha$ & OTI & 429 & 429 & 1714 & & 1742 & 448 & -051 & (2) & -062 \\
\hline$\infty 00$ & 071 & 000 & 071 & $\infty 00$ & 000 & $\infty 00$ & $\infty 00$ & 071 & 429 & 071 & 071 & 000 & 000 & 071 & 1714 & & 1742 & -062 & -039 & -003 \\
\hline 071 & 429 & 77 & 429 & 11 & 11 & . & 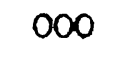 & 11 & 012 & $v$ & $\infty 00$ & o & oo & 071 & 429 & 1714 & & 42 & 8 & 448 \\
\hline$\infty$ & 071 & 000 & 071 & 000 & 000 & 071 & 071 & 429 & 071 & 000 & 000 & 071 & 071 & 429 & 429 & 429 & 1714 & & 1754 & 478 \\
\hline 071 & 000 & $\infty 00$ & $\infty 00$ & 071 & 000 & 071 & 000 & 000 & 429 & 071 & 071 & 071 & 000 & 000 & 429 & 071 & 071 & 1714 & & 742 \\
\hline 429 & 071 & 071 & 000 & 071 & 000 & 071 & $\infty$ & 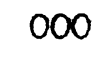 & 071 & 000 & 000 & 429 & 071 & 071 & 071 & 000 & 000 & 429 & -714 & \\
\hline 071 & 000 & 000 & 071 & 429 & 071 & 429 & 071 & 071 & OTI & $\infty 00$ & 000 & 071 & 000 & 000 & 071 & 000 & 000 & 429 & 429 & 1714 \\
\hline
\end{tabular}


D-7-5 Average variation of a treatment difference $=4.61062$

\begin{tabular}{|c|c|c|c|c|c|c|c|c|c|c|c|c|c|c|c|c|c|c|c|c|c|c|c|}
\hline 2310 & 903 & 580 & -499 & -484 & -492 & -202 & 1075 & 668 & 345 & -573 & -558 & -566 & -276 & 1067 & 660 & 072 & -563 & -548 & -556 & -265 & 1108 & 701 & 378 \\
\hline & 2277 & 665 & -313 & -342 & -414 & -134 & 624 & 997 & 386 & -272 & -302 & -373 & -094 & 552 & 926 & 275 & -217 & -247 & -318 & -039 & 582 & 955 & 44 \\
\hline 2292 & & 1834 & 326 & 286 & 151 & 386 & 290 & 374 & 544 & 411 & 370 & 235 & 470 & 155 & 239 & 1048 & 580 & 539 & 4 & 640 & 140 & 224 & 394 \\
\hline 958 & 2292 & & 3021 & 1704 & 1473 & 1152 & -567 & -380 & 259 & 1874 & 1557 & 1327 & 1005 & -797 & -610 & 1339 & 2180 & 1862 & 1632 & 1311 & -868 & -682 & -043 \\
\hline 625 & 625 & 1625 & & 2927 & 1461 & 1126 & -511 & -368 & 259 & 1512 & 1736 & 1270 & 935 & -727 & -584 & 1272 & 1807 & 2031 & 1564 & 1229 & -812 & -670 & -042 \\
\hline-583 & -583 & -250 & 2278 & & 2562 & 991 & -505 & -426 & 138 & 1219 & 1207 & 1308 & 737 & -653 & -575 & 957 & 1450 & 1437 & 1538 & 967 & -724 & -646 & -082 \\
\hline-583 & -583 & -250 & 1028 & 2278 & & 1962 & -228 & -160 & 360 & 886 & 860 & 726 & 696 & -362 & -295 & 1107 & 1073 & 1047 & 912 & 882 & -392 & 325 & 95 \\
\hline-583 & -583 & -250 & 1028 & 1028 & 2278 & & 2382 & 930 & 596 & -685 & -629 & -623 & -346 & 1138 & 686 & 005 & -686 & -630 & -624 & -347 & 1165 & 713 & 379 \\
\hline-333 & -333 & 000 & 778 & 778 & 778 & 1778 & & 2259 & 636 & -384 & -372 & -430 & -164 & 622 & 952 & 208 & -341 & -329 & -386 & -120 & 638 & 967 & 344 \\
\hline 1042 & 708 & 375 & -583 & -583 & -583 & -333 & 2292 & & 1794 & 299 & 300 & 179 & 400 & 225 & 265 & 981 & 457 & 458 & 337 & 8 & 196 & 237 & 95 \\
\hline 708 & 1042 & 375 & -583 & -583 & -583 & -333 & 958 & 2292 & & 3509 & 2147 & 1853 & 1521 & -979 & -678 & 1542 & 2525 & 2163 & 1870 & 1537 & -1061 & -761 & -077 \\
\hline 375 & 375 & 375 & -250 & -250 & -250 & $\infty 00$ & 625 & 625 & 1625 & & 3326 & 1797 & 1450 & -909 & -652 & 1476 & 2152 & 2332 & 1802 & 1456 & -1005 & -748 & -076 \\
\hline-583 & -583 & -250 & 944 & 694 & 694 & 444 & -583 & -583 & -250 & 2278 & & 2834 & 1252 & -835 & -642 & 1160 & 1795 & 1738 & 1776 & 1194 & -918 & -724 & -116 \\
\hline-583 & -583 & -250 & 694 & 944 & 694 & 444 & -583 & -583 & -250 & 1028 & 2278 & & 2211 & -544 & -362 & 1310 & 1418 & 1348 & 1149 & 08 & -585 & -403 & 61 \\
\hline-583 & -583 & -250 & 694 & 694 & 994 & 444 & -583 & -583 & -250 & 1028 & 1028 & 2278 & & 2461 & 946 & -060 & -1043 & -973 & -899 & -608 & 1252 & 737 & 339 \\
\hline-333 & -333 & 000 & 444 & 444 & 444 & 444 & -333 & -333 & 000 & 778 & 778 & 778 & 1778 & & 2212 & 143 & -698 & -672 & -662 & -382 & 726 & 991 & 305 \\
\hline 1042 & 708 & 375 & -583 & -583 & -583 & -333 & 1042 & 708 & 375 & -583 & -583 & -583 & -333 & 2292 & & 3999 & 2315 & 2249 & 1933 & 2083 & -410 & -207 & 566 \\
\hline 708 & 1042 & 375 & -583 & -583 & -583 & -333 & 708 & 1042 & 375 & -583 & -583 & -583 & -333 & 958 & 2292 & & 4323 & 2950 & 2592 & 2216 & -1170 & -825 & -027 \\
\hline 375 & 375 & 375 & -250 & -250 & -250 & $\infty 00$ & 375 & 375 & 375 & -250 & -250 & -250 & 000 & 625 & 625 & 1625 & & 4118 & 2525 & 2134 & -1113 & -812 & -026 \\
\hline-583 & -583 & -250 & 944 & 694 & 694 & 444 & -583 & -583 & -250 & 944 & 694 & 694 & 444 & -583 & -583 & -250 & 2278 & & 3499 & 1872 & -1026 & -789 & -066 \\
\hline-583 & -583 & -250 & 694 & 944 & 694 & 444 & -583 & -583 & -250 & 694 & 944 & 694 & 444 & -583 & -583 & -250 & 1028 & 2278 & & $27 \varepsilon_{i}$ & -694 & -467 & 211 \\
\hline-583 & -583 & -250 & 694 & 694 & 944 & 444 & -583 & -583 & -250 & 694 & 694 & 944 & 444 & -583 & -583 & -250 & 1028 & 1028 & 2278 & & 2584 & 1058 & 616 \\
\hline-333 & -333 & 000 & 444 & 444 & 444 & 444 & -333 & -333 & 000 & 444 & 444 & 444 & 444 & -333 & -333 & 000 & $77^{8}$ & 778 & 778 & $177^{8}$ & & 2312 & 582 \\
\hline 1042 & 708 & 375 & -583 & -583 & -583 & -333 & 1042 & 708 & 375 & -583 & -583 & -583 & -333 & 1042 & 708 & 375 & -583 & -583 & -583 & -333 & 2292 & & 1632 \\
\hline 708 & 1042 & 375 & -583 & -583 & -583 & -333 & 708 & 1042 & 375 & -583 & -583 & -583 & -333 & 708 & 1042 & 375 & -583 & -583 & -583 & -333 & 958 & 2292 & \\
\hline 375 & 375 & 375 & -250 & -250 & -250 & 000 & 375 & 375 & 375 & -250 & -250 & -250 & 000 & 375 & 375 & 375 & -250 & -250 & -250 & 000 & 625 & 625 & 1625 \\
\hline
\end{tabular}

$\underline{D-7-6}$ Average variation of a treatment difference $=4.01450$ 
D-7-3 Average variation of a treatment difference $=3.85890$

\begin{tabular}{|c|c|c|c|c|c|c|c|c|c|c|c|c|c|c|c|c|c|c|c|c|c|c|c|}
\hline 2158 & 804 & 513 & -463 & -463 & -463 & -213 & 908 & 554 & 263 & -504 & -504 & -504 & -254 & 908 & 554 & 263 & -483 & -483 & -483 & -233 & 908 & 554 & 263 \\
\hline & 2158 & 513 & -463 & -463 & -463 & -213 & 554 & 908 & 263 & -483 & 483 & -483 & -233 & 554 & 908 & 263 & $-5 \alpha_{4}$ & -504 & -504 & -254 & 554 & 908 & 263 \\
\hline 2242 & & 1575 & -025 & -025 & -025 & 225 & 263 & 263 & 325 & -088 & -088 & -088 & 163 & 263 & 263 & 325 & $-\infty 68$ & -088 & $-\infty 88$ & 163 & 263 & 263 & 325 \\
\hline 885 & 2311 & & 2425 & 1175 & 1175 & 925 & 463 & -463 & -025 & 988 & 738 & 738 & 488 & -463 & -463 & $-\infty 5$ & 988 & 738 & 738 & 488 & -463 & -463 & -025 \\
\hline 435 & 409 & 3086 & & 2425 & 1175 & 925 & -463 & -463 & -025 & 738 & 988 & 738 & 488 & -463 & -463 & $-\infty 25$ & 738 & 988 & 738 & 488 & -463 & -463 & -025 \\
\hline 452 & -481 & 866 & 2427 & & 2425 & 925 & 463 & -463 & -025 & 738 & 738 & 988 & 488 & -463 & -463 & $-\infty e 5$ & 738 & 738 & 988 & 488 & -463 & -463 & -025 \\
\hline-391 & -446 & 1012 & 1228 & 2562 & & 1925 & -213 & -213 & 225 & 488 & 488 & 488 & 488 & -213 & -213 & 225 & 488 & 488 & 488 & 488 & -213 & -213 & 225 \\
\hline-426 & -501 & 857 & 1148 & 1216 & 2402 & & 2258 & 804 & 513 & $-50 \mathrm{H}_{4}$ & -504 & -504 & -254 & 908 & 554 & 263 & -483 & -483 & -483 & -233 & 08 & 554 & 263 \\
\hline .187 & -216 & 1111 & 877 & 943 & 863 & 1857 & & 2158 & 513 & 483 & 483 & 483 & -233 & 554 & 908 & 263 & -504 & -504 & -504 & -254 & 554 & 908 & 263 \\
\hline 946 & 615 & 034 & -552 & -510 & -530 & -272 & 2283 & & 1575 & -088 & -088 & -088 & 163 & 263 & 263 & 325 & -088 & -088 & -088 & 163 & 263 & 263 & 325 \\
\hline 589 & $10_{+1}$ & $\infty 08$ & -582 & -564 & -604 & -301 & 852 & 2304 & & 2258 & 1008 & 1008 & 758 & -504 & -483 & -088 & 904 & 654 & 654 & 404 & -504 & -483 & -088 \\
\hline 326 & 355 & 574 & -112 & -050 & -110 & 168 & 544 & 572 & 1624 & & 2258 & 1008 & 758 & -504 & -483 & -088 & 654 & 904 & 654 & 404 & -504 & -483 & -088 \\
\hline$\cdot 346$ & -414 & 685 & 1121 & 968 & 888 & 591 & -472 & -541 & -032 & 2599 & & 2258 & 758 & -504 & -483 & -088 & 654 & 654 & 904 & 404 & $-50_{4}$ & -483 & -088 \\
\hline-285 & -379 & 832 & 922 & 1301 & 956 & 657 & -430 & -523 & 030 & 1445 & 2825 & & 1758 & -254 & -233 & 163 & 404 & $4 \alpha_{4}$ & 404 & 404 & -254 & -233 & 163 \\
\hline-320 & -434 & 677 & 842 & 956 & 1141 & 577 & 450 & -563 & -030 & 1365 & 1480 & 2665 & & 2158 & 804 & 513 & -483 & -483 & -483 & -233 & 908 & 54 & 63 \\
\hline-081 & -149 & 930 & 571 & 683 & 603 & 571 & -192 & -261 & 248 & 1069 & 1180 & 1200 & 2069 & & 2158 & 513 & -504 & -504 & -504 & -254 & 554 & 908 & 263 \\
\hline 931 & 600 & 039 & -502 & -474 & -494 & -252 & 904 & 572 & 264 & -442 & -415 & 435 & -192 & 2154 & & 1575 & -088 & -088 & -088 & 163 & 263 & 263 & 325 \\
\hline 574 & 1026 & $\alpha_{3}$ & -531 & -529 & -561 & -281 & 572 & 1204 & 292 & -511 & -508 & -548 & -261 & 822 & 2274 & & 2258 & 1008 & 1008 & 758 & 483 & -504 & -088 \\
\hline 311 & 340 & 579 & -062 & -014 & .074 & 188 & 264 & 292 & 343 & -002 & 045 & -015 & 248 & 514 & 542 & 1594 & & 2258 & 1008 & 758 & -483 & -504 & -088 \\
\hline 432 & -461 & 526 & 1027 & 848 & 768 & 517 & -513 & -541 & -072 & 1081 & 902 & 822 & 571 & -502 & -531 & -062 & 2347 & & 2258 & 758 & -483 & 504 & -088 \\
\hline -371 & 426 & 672 & 828 & 1182 & 836 & 583 & 470 & -524 & .010 & 928 & 1281 & 936 & 683 & -474 & -529 & -014 & 1168 & 2521 & & 1758 & -233 & -254 & 163 \\
\hline 406 & $-48 I$ & 517 & 748 & 836 & 1022 & 503 & -490 & -564 & -070 & 848 & 936 & 1121 & 603 & -494 & -569 & -074 & 1088 & 1176 & 2362 & & 2158 & 804 & 513 \\
\hline-167 & -196 & 771 & 477 & 563 & 482 & 497 & -232 & -261 & 208 & 551 & 637 & 557 & 571 & -252 & -281 & 188 & 837 & 923 & 843 & 1857 & & 2158 & 513 \\
\hline 957 & 580 & 030 & -532 & -486 & -491 & -267 & 926 & 549 & 266 & -426 & -380 & -385 & -161 & 911 & 534 & 251 & -512 & -466 & -471 & -247 & 2202 & & 1575 \\
\hline 600 & 1006 & oOl & -561 & -541 & -566 & -296 & 595 & 1001 & 296 & -494 & -474 & -499 & 229 & 580 & 986 & 280 & -541 & -521 & -546 & -276 & 825 & 2231 & \\
\hline 337 & 320 & 570 & -092 & .026 & 71 & 173 & 286 & 269 & 6 & 14 & 080 & 035 & 279 & 271 & 254 & 331 & -072 & -006 & -051 & 193 & +2 & 525 & 02 \\
\hline
\end{tabular}


D-7-1 Average variation of a treatment difference $=3.81130$

\begin{tabular}{|c|c|c|c|c|c|c|c|c|c|c|c|c|c|c|c|c|c|c|c|c|c|c|c|}
\hline 2147 & 785 & 481 & -516 & -516 & -516 & -266 & 897 & 535 & 231 & -545 & -545 & -545 & -295 & 897 & 535 & 231 & -516 & -516 & -516 & -266 & 897 & 535 & 231 \\
\hline & 2109 & 452 & -561 & -561 & -561 & -311 & 535 & 859 & 202 & -571 & -571 & -571 & -321 & 535 & 859 & 202 & -561 & -561 & -561 & -311 & 535 & 859 & 201 \\
\hline 2245 & & 1481 & -183 & -183 & -183 & 673 & 231 & 202 & 231 & -212 & -212 & -212 & 039 & 231 & 202 & 231 & -183 & -183 & -183 & 067 & 231 & 202 & 231 \\
\hline 912 & 2245 & & 2160 & 910 & 910 & 660 & -516 & -561 & -183 & 782 & 532 & 532 & 282 & -516 & -561 & -183 & 827 & 577 & 577 & 327 & -516 & -516 & -183 \\
\hline 579 & 579 & 1579 & & 2160 & 910 & 660 & -516 & -561 & -183 & 532 & 782 & 532 & 282 & -516 & -561 & -183 & 577 & 827 & 577 & 327 & -516 & -516 & -183 \\
\hline-477 & -477 & -144 & 2143 & & 2160 & 660 & -516 & -561 & -183 & 532 & 532 & 782 & 282 & -516 & -561 & -183 & 577 & 577 & 827 & 327 & -516 & -516 & -183 \\
\hline-490 & -490 & -157 & 894 & 2161 & & 1660 & -266 & -311 & 067 & 282 & 282 & 282 & 282 & -266 & -311 & 067 & 327 & 327 & 327 & 327 & -266 & -311 & 067 \\
\hline-523 & -523 & -190 & 861 & 869 & 2094 & & 2147 & 785 & 481 & -545 & -545 & -545 & -295 & 897 & 535 & 231 & -516 & -516 & -516 & -266 & 897 & 535 & 231 \\
\hline-227 & -227 & 106 & 643 & 644 & 611 & 1644 & & 2109 & 452 & -571 & -571 & -571 & -321 & 535 & 859. & 202 & -561 & -561 & -561 & -311 & 535 & 859 & 202 \\
\hline 982 & 649 & 316 & 476 & -473 & -515 & -226 & 2235 & & 1481 & -212 & -212 & -212 & 039 & 231 & 202 & 231 & -183 & -183 & -183 & 067 & 231 & 202 & 231 \\
\hline 649 & 982 & 316 & -476 & -473 & -515 & -226 & 902 & 2235 & & 2090 & 840 & 840 & 590 & -545 & -571 & -212 & 782 & 532 & 532 & 282 & -545 & -571 & -212 \\
\hline 316 & 316 & 316 & -143 & -140 & -182 & 107 & 569 & 569 & 1569 & & 2090 & 840 & 590 & -545 & -571 & -212 & 532 & 782 & 532 & 282 & -545 & -571 & -212 \\
\hline-477 & -477 & -144 & 810 & 561 & 528 & 310 & -476 & -476 & -143 & 2143 & & 2090 & 590 & -545 & -571 & -212 & 532 & 532 & 782 & 282 & -545 & -571 & -212 \\
\hline-490 & -490 & -157 & 561 & 828 & 536 & 311 & -473 & -473 & -140 & 894 & 2161 & & 1590 & -295 & -321 & 039 & 282 & 282 & 282 & 282 & -294 & -321 & 039 \\
\hline-523 & -523 & -190 & 528 & 536 & 761 & 278 & -515 & -515 & -182 & 861 & 869 & 2094 & & 2147 & 785 & 481 & -516 & -516 & -516 & -266 & 897 & 535 & 231 \\
\hline-227 & -227 & 106 & 310 & 311 & 278 & 310 & -226 & -226 & 107 & 643 & 644 & 611 & 1643 & & 2109 & 452 & -561 & -561 & -561 & -311 & 535 & 859 & 202 \\
\hline 949 & 616 & 282 & -510 & -515 & -540 & -260 & 944 & 610 & 277 & -510 & -515 & -540 & -260 & 2169 & & 1481 & -183 & -183 & -183 & 067 & 231 & 202 & 231 \\
\hline 616 & 949 & 282 & -510 & -515 & -540 & -260 & 610 & 944 & 277 & -510 & -515 & -540 & -260 & 835 & 2269 & & 2160 & 910 & 910 & 660 & -516 & -561 & -183 \\
\hline 282 & 282 & 282 & -177 & -182 & -207 & 078 & 278 & 277 & 277 & -176 & -182 & -207 & 074 & 502 & 502 & 1502 & & 2160 & 910 & 660 & -516 & -561 & -183 \\
\hline-477 & -477 & -144 & 810 & 561 & 528 & 310 & -476 & -476 & -143 & 810 & 561 & 528 & 310 & -510 & -510 & -176 & 2143 & & 2160 & 660 & -516 & -561 & -183 \\
\hline-490 & -490 & -157 & 561 & 828 & 536 & 310 & -473 & -473 & -140 & 561 & 828 & 536 & 310 & -515 & -515 & -182 & 894 & 2161 & & 1660 & -266 & -311 & 067 \\
\hline-523 & -523 & -190 & 528 & 536 & 761 & 278 & -515 & -515 & -182 & 528 & 536 & 761 & 278 & -540 & -540 & -207 & 861 & 869 & 2094 & & 2147 & 785 & 481 \\
\hline-227 & -227 & 106 & 310 & 311 & 278 & 310 & -226 & -226 & 107 & 310 & 311 & 278 & 310 & -260 & -260 & 074 & 643 & 644 & 611 & 1644 & & 2109 & 452 \\
\hline 995 & 662 & 329 & -477 & -490 & -523 & -227 & 982 & 649 & 316 & -477 & -490 & -523 & -227 & 949 & 616 & 282 & -477 & -490 & -523 & -227 & 2245 & & 1481 \\
\hline 662 & 995 & 329 & -477 & -490 & -523 & -227 & 649 & 982 & 316 & -477 & -490 & -523 & -227 & 616 & 949 & 282 & -477 & -490 & -523 & -227 & 912 & 2245 & \\
\hline 329 & 329 & 329 & -144 & -157 & -190 & 106 & 316 & 316 & 316 & -144 & -157 & -190 & 106 & 282 & 282 & 282 & -144 & -157 & -190 & 106 & 579 & 579 & 1579 \\
\hline
\end{tabular}

D-7-2 Average variation of a treatment difference $=3.82798$ 


\begin{tabular}{|c|c|c|c|c|c|c|c|c|c|c|c|c|c|c|c|c|c|c|c|c|c|c|c|c|c|c|c|}
\hline 2000 & 571 & 571 & 571 & 143 & -143 & $\infty 00$ & 000 & 143 & 143 & 000 & 000 & 000 & 000 & 571 & 143 & 000 & 571 & $\infty 00$ & 143 & 000 & 571 & $\infty 00$ & 143 & -143 & -143 & 000 & $\infty 00$ \\
\hline & 2000 & 571 & 571 & 143 & -143 & 000 & 000 & 000 & 000 & 571 & 143 & -143 & -143 & 000 & 000 & -143 & 000 & -143 & $\infty 00$ & 000 & 143 & $\infty 00$ & 571 & 000 & $\infty 00$ & 571 & 143 \\
\hline 1672 & & 2000 & 571 & 000 & 000 & 571 & 143 & -143 & -143 & 000 & 000 & 000 & 000 & 143 & 571 & -143 & $\infty 00$ & -143 & 000 & -143 & 000 & -143 & 000 & 000 & 000 & 143 & 571 \\
\hline 307 & 1735 & & 2000 & 000 & 000 & 143 & 571 & 000 & $\infty 00$ & 143 & 571 & -143 & -143 & 000 & 000 & 000 & 143 & 000 & 571 & -143 & 000 & -143 & 000 & -143 & -143 & OD & bo \\
\hline 404 & 352 & 2119 & & 2000 & 571 & 571 & 571 & 571 & 000 & 000 & 143 & 571 & 000 & 000 & 143 & -143 & -143 & $\infty$ & 000 & 571 & 000 & 143 & 000 & -143 & 000 & -143 & $\infty 00$ \\
\hline 404 & 530 & 544 & 2119 & & 2000 & 571 & 571 & 000 & -143 & -143 & 000 & $\infty 00$ & -143 & $3-143$ & 000 & 000 & $\infty 00$ & 571 & 143 & 143 & 000 & 571 & $\infty 00$ & $\infty 00$ & 571 & 000 & 143 \\
\hline 014 & -080 & -237 & -223 & 2119 & & 2000 & 571 & 000 & -143 & -143 & 000 & 143 & 000 & 000 & 571 & -143 & -143 & 000 & 000 & $\infty 00$ & -143 & 000 & -143 & 000 & 143 & 000 & 571 \\
\hline 087 & 087 & 014 & 112 & 404 & 672 & & 2000 & 143 & 000 & 000 & 571 & $\infty 00$ & -143 & -143 & 000 & 000 & $\infty 00$ & 143 & 571 & 000 & -143 & $\infty 00$ & -143 & -143 & $\infty$ & -143 & 000 \\
\hline 112 & 028 & 352 & -031 & 530 & 307 & 1735 & & 2000 & 571 & 571 & 571 & 571 & 143 & $\infty 00$ & 000 & 000 & -143 & -143 & 000 & 571 & $\infty 00$ & $\infty 00$ & 143 & $\infty 00$ & -143 & $\infty 00$ & -143 \\
\hline 112 & 206 & -223 & 544 & 544 & $4 \mathrm{O}_{4}$ & 352 & 2119 & & 2000 & 571 & 571 & 143 & 571 & 000 & $\infty 00$ & 571 & $\infty 00$ & $\infty 00$ & 143 & 000 & -143 & -143 & 000 & 571 & 000 & 143 & 000 \\
\hline-059 & -185 & 192 & -237 & 544 & 112 & 206 & -223 & 2119 & & 2000 & 571 & 000 & 000 & 143 & -143 & 000 & -143 & -143 & $\infty$ & 143 & $\infty 00$ & 000 & 571 & 143 & 000 & 571 & $\infty 00$ \\
\hline 014 & 066 & 348 & 192 & -223 & 014 & -080 & -237 & 544 & 2119 & & 2000 & 000 & 000 & -143 & -143 & 143 & 000 & 000 & 571 & 000 & -143 & -143 & 000 & 000 & -143 & $\infty$ & -143 \\
\hline-059 & 307 & 014 & -059 & 112 & 087 & 087 & 014 & $4 \mathrm{Ol}_{4}$ & 404 & 1672 & & 2000 & 571 & 571 & 571 & 000 & $\infty 00$ & -143 & -143 & 571 & 143 & 000 & 000 & 000 & -143 & -143 & $\infty 00$ \\
\hline 038 & 101 & 206 & 530 & -031 & 112 & $\infty 28$ & 352 & 352 & 530 & 307 & 1735 & & 2000 & 571 & 571 & 571 & 143 & 000 & 000 & 000 & 000 & -143 & -143 & 571 & 000 & 000 & 143 \\
\hline 038 & $\mathrm{OO}_{4}$ & -185 & -080 & 530 & 038 & 101 & 206 & 352 & -031 & 112 & 028 & 1735 & & 2000 & 571 & 143 & 571 & $\infty 00$ & $\infty$ & 143 & 571 & 000 & 000 & 000 & -143 & -143 & 000 \\
\hline 112 & 254 & -028 & 348 & -237 & -059 & -185 & 192 & -223 & 544 & 112 & 206 & 352 & 2119 & & 2000 & 000 & 000 & -143 & -143 & $\infty 00$ & 000 & -143 & -143 & -143 & $\infty$ & 000 & 571 \\
\hline 404 & 066 & -310 & -028 & 192 & 014 & 066 & 348 & -237 & -223 & 014 & -080 & 530 & 544 & 2119 & & 2000 & 571 & 571 & 571 & -143 & $\infty$ & 000 & -143 & 571 & 143 & $\infty 00$ & $\infty$ \\
\hline 136 & 112 & 404 & 112 & -059 & -059 & 307 & 014 & 014 & 112 & 087 & 087 & 307 & 404 & 404 & 1672 & & 2000 & 571 & 571 & $\infty 00$ & 571 & 143 & 000 & 000 & 000 & -143 & -143 \\
\hline 112 & 004 & 254 & 066 & -080 & 038 & 004 & -185 & 206 & 530 & 038 & 101 & 08 & 352 & -031 & 112 & 1735 & & 2000 & 571 & 000 & 143 & 571 & $\infty$ & 143 & 571 & 000 & $\infty 00$ \\
\hline $4 \alpha_{4}$ & -185 & -028 & -310 & 348 & 112 & 254 & -028 & 192 & -237 & -059 & -185 & 206 & -223 & 544 & 112 & 352 & 2119 & & 2000 & -143 & 000 & 000 & -143 & $\infty 00$ & 000 & -143 & -143 \\
\hline 112 & -080 & 348 & -028 & -028 & 404 & 066 & -310 & 348 & 192 & 014 & 066 & $-\infty 80$ & -237 & -223 & 014 & 530 & 544 & 2119 & & 2000 & 571 & 571 & 571 & -143 & 000 & $\infty 00$ & -143 \\
\hline 136 & 038 & 112 & 404 & 112 & 136 & 112 & 404 & 014 & -059 & -059 & 307 & 087 & 014 & 112 & 087 & 307 & 404 & 404 & 1672 & & 2000 & 571 & 571 & -143 & $\infty 00$ & 000 & -143 \\
\hline-059 & 038 & -059 & 014 & 404 & 136 & 038 & 112 & $4 \mathrm{O}_{4}$ & 112 & 136 & 112 & 307 & 014 & -059 & -059 & 087 & 014 & 112 & 087 & 1672 & & 2000 & 571 & 000 & 571 & 143 & 000 \\
\hline 307 & 101 & -185 & 066 & 066 & 112 & $00_{4}$ & 254 & -185 & -080 & 038 & 004 & 101 & 206 & 530 & 038 & 028 & 352 & -031 & 112 & 307 & 1735 & & 2000 & 000 & 143 & 571 & $\infty 00$ \\
\hline 014 & 206 & 192 & 348 & -310 & 404 & -185 & -028 & -028 & 348 & 112 & 254 & -185 & 192 & -237 & -059 & 206 & -223 & 544 & 112 & 404 & 352 & 2119 & & 2000 & 571 & 571 & 571 \\
\hline-059 & 530 & -237 & 192 & -028 & 112 & -080 & 348 & -310 & -028 & 404 & 066 & 066 & 348 & 192 & 0.14 & -080 & 237 & -223 & 014 & 404 & 530 & 544 & 2119 & & 2000 & 571 & 571 \\
\hline 087 & 112 & 112 & 014 & 014 & -059 & 038 & -059 & 112 & $40_{4}^{4}$ & 136 & 038 & 112 & 404 & 112 & 014 & 307 & 014 & -059 & -059 & 087 & 087 & 014 & 112 & 1672 & & 2000 & 571 \\
\hline 087 & 028 & 206 & -080 & 066 & 307 & 101 & -185 & 254 & 066 & 112 & $\infty d_{4}$ & 004 & -185 & -080 & 038 & 101 & 206 & 530 & 038 & 112 & 028 & 352 & -031 & 307 & 1735 & & 2000 \\
\hline 014 & 352 & -223 & -236 & 348 & 014 & 206 & 192 & -028 & -310 & 404 & -185 & 254 & -028 & 348 & 112 & -185 & 192 & -237 & -059 & 112 & 206 & -223 & 544 & 404 & 352 & 2119 & \\
\hline 112 & 031 & 544 & -223 & 192 & -059 & 530 & -237 & 348 & -028 & 112 & -080 & 066 & -310 & -028 & 404 & 066 & 348 & 192 & 014 & 014 & -080 & -237 & -223 & 404 & 530 & 544 & 2119 \\
\hline
\end{tabular}

$\underline{D-7-10}$ Average variation of a treatment difference $=3.59350$ 